\title{
Delich, la fuerza de la convicción
}

Horacio Crespo $^{1}$

«La muerte es una vida vivida» apuntó -conciso, certero-Jorge Luis Borges. Para infelicidad de su familia y amigos, el tiempo de Francisco Delich dibujó ya su término definitivo, llegó a su destino cumplido, y abrió la interrogación que toda «vida vivida» propone, el de las preguntas que se enuncian sustentadas en la distancia inexorable abierta entre un proyecto de existencia y su azaroso cumplimiento.La tensión entre autenticidad, entendida como una vida que asume la libertad consustancial a nuestro ser, de realización plena, consciente y sin concesiones del propio proyecto vital, y mala fe, conducta que intenta esconder la responsabilidad de los propios actos, esinherente a toda existencia.Lo que en definitiva importa es como se resuelve. Certezas, ambigüedades, silencios que construyen una biografía, aquello de lo que nos habló Sartre, y que Francisco Delich, como genuino miembro de una generación que tuvoal autor de Los caminos de la libertad entre sus mentores, no soslayaría señalar para los demás, ni mucho menos para sí mismo.Y en este asunto esencial, más allá de opiniones y juicios encomiásticos, polémicos o adversos que se quieran y se deban formular sobre su trayectoria y labor como intelectual y hombre público, no debe soslayarse una certeza primera: el Polaco - no puedo eludir el apelativo inconfundible y afectuoso-vivió y actuó de acuerdo consigo mismo, conforme a sus creencias y convicciones, no se apartó de ellas. Lo hizo a su modo enérgico, voluntarioso, nunca desviado de la honradez material y de espíritu: un ejemplo necesario, hoy más que nunca.

Delich fue afortunado en alcanzar esa zona de contornos un tanto imprecisos al que rotunda y definitivamente lo había conducido su madurez: la de la sonrisa afable inescindible del guiño irónico, la de las preguntas críticas sin respuestas unívocas, la de la afirmación convincente que dejaba abierta, sin embargo, el intersticio constructivo de la duda, la de la revisión serena de los pasos cumplidos, tal como hizo en su libro 808 días

\footnotetext{
${ }^{1}$ Docente de la Universidad Autónoma del Estado de Morelos (México) y de la Universidad Nacional de San Martín (UNSAM).
} 
con su memorable rectorado normalizador de la Universidad de Buenos Aires. En parte, resulta paradójico que sea éste, el de la recoleta meditación de su retiro, el lugar en el que prefiero mirarlo, proseguir un diálogo ahora ya finalmente inmaterial, imaginario. Digo paradójico referido a éla quien conocí hace ya casi cincuenta años y al que acompañé sencillamente con cercanía de amigo, satisfacción y compromiso en algún tramo de sus responsabilidades en nuestra Universidad de Córdoba-, un hombre al que dominaba la inquietud de la acción: la pasión de la acción educativa, la turbulencia de la acción política, la preocupación de la acción ciudadana. Actuar para construir, actuar para transformar. Delich creía, tenía certezas y sostenía posiciones, y esto califica ciertamente su personalidad en un tiempo en el que crecientemente el cinismo y el oportunismo han desplazado a las convicciones.

Posiblemente, casi seguramente, allí radicase su fuerza, su capacidad de influir y de convencer, el poder de la confianza que transmitía acerca de que algo siempre es posible hacer, que a pesar de las fuerzas inertes es posible cambiar, y cambiar para mejor. No sé si el adjetivo es plenamente ajustado, pero no vacilo en aplicárselo: una vocación sarmientina por el hacer, un protagonismo sin pausa de vitalidad social. Y, sin embargo, como dije, en estos días del progresivo atardecer regreso al Delich del último tiempo, a quien por lejanía geográfica que impone la residencia debo imaginar e intuir más que recordar, porque serena y ejemplarmente fue capaz de seguir pensando críticamente hacia adelante, sostener «una mirada distinta, una mirada en la cual están mucho más pensados los próximos treinta años que esos treinta años pasados» desde 1983, como dijo en la presentación -que fue un balance ajustado y también, en cierta forma, una mensaje de partida- de su mencionado libro acerca de la universidad y los tiempos iniciales de ciclo democrático, como gustaba calificar al periodo que arrancó en diciembre de 1983 y que lo tuvo como protagonista fundamental. Pensar sin complejos una época que viene, que suponía será necesaria y quizás radicalmente distinta, y a la que se asomaba, como siempre, con imaginación, audacia intelectual e, inclusive, cierta encantadora y deliberada ingenuidad. Una incitación a la novedad que depara la proyección hacia el futuro, una cierta manera de estar de todos modos en él.

Delich ha dejado huella en la historia de Córdoba y en la del país. Córdoba fue núcleo de los antagonismos sociales y políticos de la Argentina de los años cincuenta y sesenta,territorio del Cordobazo como paradigma de levantamiento urbano, sede de la irrupción del sindicalismo clasista, de las relaciones fluidas entre izquierda peronista y socialista, de la unidad 
obrero-estudiantil declamada y practicada con alcances de inesperada masividad, de la radicalización de la juventud católica. Estas fueron las bases de lo que Aricó llamó, con atinada percepción, laTurin latinoamericana, recogiendo la traza de Gramsci y la coyuntura de innovación de prodigiosa creatividad de la «nueva izquierda» europea, desde la heterodoxia de Togliatti a los fuegos del mayo del $68 \mathrm{y}$ del «otoño caliente» italiano del siguiente año. Fue en esta Córdoba en la que Delich -hijo de inmigrantes, de quienes seguramente recibió la lección primera de encomiable austeridad que caracterizó toda su existencia pública y privada- nació, creció y se formó; esa Córdoba del barrio Alberdi y su impronta popular que nunca abandonó así como su pasión por Belgrano, el club celeste fundado por Arturo Orgaz, el prócer de la Reforma. Su trayectoria y su personalidad no pueden escindirse del aprendizaje en la bohemia inolvidable de las calles estudiantiles del Clínicas, con su corazón en la casona de la calle Sol de Mayo de la Federación Universitaria que presidió en los tiempos del rectorado de Jorge Orgaz, y también en la militancia en la Reforma de la que sería a lo largo de toda su vida uno de sus últimos grandes protagonistas políticos e intelectuales.

Desde su temprano diálogo con Aricó, creo que Delich asumió plenamente la nueva mirada sobre Córdoba, signada por una forma distinta de registrar la realidad de la modernización y apropiarse y reescribir su tradición cultural. Hay que subrayar siempre que junto a los refinamientos de la sociología francesa en la que se formó en el París de los primeros sesenta con Alain Touraine como mentor, participó destacadamente en la experiencia inicial de Pasado y Presente, y esta es una filiación política, intelectual y cultural fundamental en su biografía.

Protagonista político y partícipe activo de la intelectualidad comprometida en la lucha anti-dictatorial y en la transformación social del país, fue parte y dio cuenta de la caracterización de esa Córdoba marcada por la impetuosa transformación de la aldea monástica y turbulenta que imaginó Sarmiento y evocó Capdevila, tal como lo apuntóen su temprano libro sobre el Cordobazo(1970),Crisis y protesta social, Córdoba, mayo de 1969, hoy ya un verdadero clásico de la sociología argentina. Y en Tierray conciencia campesina en Tucumán, editado también por Aricó en 1970, realizó un estudio del que Walter Mignolo, en una temprana reseña publicada en Caravelle en 1971, señalaba la voluntad tanto de dar cuenta del sindicalismo agrarista de acción reformista como la de aplicar los instrumentos teóricos y metodológicos desarrollados por la sociología estadounidense y europea para «mirar desde adentro» a América Latina. 
La idea de Córdoba como encrucijada de caminos, tanto materiales como ideales, como punto privilegiado de fusión civilizatoria. Esa ideafuerza de Aricó de Córdoba como «ciudad de frontera» que ha alimentado los esfuerzos intelectuales de toda una notable generación y de la que Delich no estuvo ajeno. En la que la larga duración supera en mucho la perspectiva primera de la historia «nacional»: es un «tiempo americano», tiempo reminiscente de los siglos barrocos de su constitución primera y fundacional. No en vano, en alguna oportunidad el Delich profesor expresó la posibilidad de un horizonte en el que la indagación teológica renovada pudiera regresar a la alta casa de estudios, en la que se desplegó por más de dos siglos, como parte natural de la más elevada preocupación filosófica. $\mathrm{O}$, tampoco pintoresco o casual, que el Delich rector restaurara con fuerza la noción del fundacional pasado jesuita que en los inmediatos años posteriores se materializó en rescate patrimonial de singular importancia histórica y simbólica y gran belleza artística.

Esta noción del espesor cultural de una ciudad «docta» en la que la Universidad se constituyó en fuente de sentido histórico estuvo presente en una de las empresas educacionales y culturales más relevantes de una trayectoria singularmente rica en ellas. Me refiero al rectorado de Francisco Delich de la casa de Trejo, cuyo balance histórico integral sería todavía prematuro hacer, pero de cuya trascendencia no caben dudas. Fue la base de una dinámica de transformación y de logros consensuales para un aggiornamiento de urgente necesidad a la que gestiones rectorales posteriores han contribuido decisivamente, pero que encuentra en esos años el impulso y modelamiento inicial. Lo fundamental fue la recuperación de la autoestima y de la conciencia del valor institucional, un mirarse hacia adentro como precondición del cambio constructivo y la aventura intelectual imprescindible. La Universidad de Córdoba del futuro tiene ese momento fundacional en el rectorado de Delich, y en ese sentido no es abusivo colocarlo en la línea de los grandes renovadores culturales de la Universidad, de la ciudad, y por la gravitación y peso natural de la misma, de la Argentina: el deán Funes, los rectores Manuel Lucero, Sofanor Novillo Corvalán y Jorge Orgaz, y las figuras estelares de la modernidad que fueron Deodoro Roca, Saúl Taborda y José Aricó. Esta afirmación no es para reanimar enconos mezquinos ya superados, propios de la disidencia política normal en la práctica democrática; seguramente no lo es en este momento de laudatio postuma, sino que constituye una sopesada proposición que subraya la significación de su paso por la máxima dignidad de nuestra cuatricentenaria institución. 
Un punto, finalmente. Delich fue un hombre importante en la transición democrática argentina y de América Latina. Sería extenderme más allá de los ceñidos espacios de este homenaje argumentar sobre este punto de reconocimiento. Sólo debo señalar que contribuyó decididamente a finales de la década de 1970 en el gran debate intelectual latinoamericano que revalorizó la democracia política y produjo la idea de la transición hacia ella, como ha mostrado Cecilia Lesgart. Un revalorización de la política como espacio de reglas consensuadas y ámbito de dialogicidad necesaria entre la pluralidad de actores que supone la complejidad de la sociedad actual. Fruto y resultado de una meditación colectiva que lo tuvo entre sus esenciales animadores, en CLACSO, en la revista Crítica \& Utopía, en esa Universidad itinerante constituida en la comunidad latinoamericana del exilio, en la publicación de textos motivadores, en la organización y el debate el debate en simposios y congresos.

Hombre de su tiempo, se animó a luchar contra lo peor de su tiempo, contra los autoritarismos y las dictaduras. Lo hizo con sencillez, sin alardes, con la fuerza de la convicción y de las razones. La force tranquille de su admirado Mitterrand. Creyendo profundamente en la educación como factor fundamental de cambio y mejoramiento social. Actuó con sinceridad y modestia, sin alardes pero con firmeza. Con la convicción de la honestidad como valor personal y ciudadano, sabiendo que la corrupción destruye inevitablemente el tejido social, degrada profundamente la convivencia democrática y compromete gravemente en la conciencia de los ciudadanos el futuro de opciones transformadoras que la admitan. Cuando el Rector de la Universidad Nacional de Córdoba o el Director de la Biblioteca Nacional revolvía sus bolsillos para pagar el sencillo café de los invitados a su oficina traído de un establecimiento cercano, daba una lección mucho más rotunda y valiosa que cualquier discurso. La inapelable retórica del gesto: austeridad, sencillez, honestidad en el ejercicio de la función pública. Respeto por los bienes sociales. Lección, entre nosotros, gente de Córdoba, de la Reforma Universitaria, del mejor heredero de los Orgaz. 